\title{
Sistema de protecção à infância em Portugal - Uma área de intervenção e estudo do Serviço Social
}

\author{
Jorge Manuel L. Ferreira \\ Universidade Lusíada de Lisboa \\ ISCTE - Instituto Universitário Lisboa
}

Este artigo mantém a ortografia vigente em Portugal

Sistema de protecção à infância em Portugal - Uma área de intervenção e estudo do Serviço Social Resumo: Este artigo procura sistematizar elementos de análise e de reflexão sobre o sistema de protecção à infância em Portugal, como área de intervenção e estudo do Serviço Social. Analisa o problema da criança integrada em contextos sociais, familiares e culturais desfavorecidos que limitam a concretização dos seus direitos e do seu bem-estar. Questiona algumas dimensões do problema que constitui objecto de estudo do Serviço Social no quadro do modelo social europeu, bem como do modelo de coordenação aberta das políticas sociais de protecção à infância e à família.

Palavras-chave: bem-estar, criança, Serviço Social, modelos de intervenção, sistema de protecção.

\section{System of Childhood Protection in Portugal - a Field of Intervention and Study of Social Work}

Abstract: This article seeks to systematize elements of analysis and reflection about the childhood protection system in Portugal, as a field of intervention and study of Social Work. It analyzes the problem of children who are in unfavorable social, family and cultural contexts that limit the realization of their rights and their well-being. It questions some dimensions of the problem that constitute the object of study of Social Work in the framework of the European social model, as well as the model for an open coordination of social policies for protection of childhood and the family.

Key words: well-being, childhood, Social Work, intervention models, protection system. 


\section{Introdução}

Este texto foi produzido a partir de pesquisas feitas ao longo do desenvolvimento da teste de doutorado Serviço Social e modelos de bem-estar para a infância: modus operandi do assistente social na promoção da protecção à criança e à família (FERREIRA, 2009). No projecto de pesquisa original, foram feitas entrevistas com assistentes sociais, realizadas entre 2005 e 2006, cabendo ressaltar que foram respeitados todos os pressupostos e princípios éticos, em se tratando de pesquisas que envolvem seres humanos e que todos os depoimentos aqui registrados foram devidamente autorizados para publicação pelos depoentes ou entrevistados, em nível de consentimento livre e esclarecido.

Os dados recolhidos pela investigação original (FERREIRA, 2009), informam-nos que as causas da situação e dos problemas sociais respeitantes à criança e à família, são: absentismo escolar, negligência familiar, falta de comunicação, excesso de consumo de álcool, violência doméstica, negligência nos cuidados de higiene e alimentação, agressividade latente na escola, passagem fácil ao acto, desestruturação familiar, sendo que muitos dos pais vivenciaram os mesmos problemas em criança. Os assistentes sociais, participantes na investigação, identificaram também situações graves de problemas económicos, famílias com percurso de institucionalização, vulnerabilidade familiar, divórcio/separação dos pais e incumprimento na regulação do exercício do poder paternal.

Essas questões remetem-nos para o debate do espaço privado da criança/jovem no quadro dos sistemas de bem-estar social, ou seja: identificamos toda a centralidade dos modelos de protecção no espaço público, incluindo neste a sociedade civil e o Estado, havendo dificuldades em identificar o espaço privado da criança. Espaço este identificado com a dimensão da participação e livre expressão da criança, direito consagrado na Convenção dos Direitos da Criança (UNICEF, 1999, art. 12), enquanto expoente máximo da garantia social de promoção da criança/jovem. Importa definir que o conceito de Criança usado é o expresso no artigo primeiro da citada convenção.

Para Falcão (1979, p. 97), “[...] os valores são, hoje, questão fundamental para as profissões que actuam na problemática humana e social, pois não é possível ignorar as contradições agudas da realidade em que vivemos." Paulo Netto (1992) considera que o Serviço Social responde, apenas, a necessidades sociais prático-empíricas, colocando a ênfase no quadro da profissão e não de um saber técnico-científico, ou seja: no domínio das práticas dominantes, desenvolvendo sobre a prática um questionamento contínuo que se transforma em quadros teóricos de referência à intervenção.
A construção do objecto do Serviço Social faz-se, no contex to institucional, numa correlação de forças entre o exercício profissional, as percepções do real, a representação social e a manifestação de interesses tanto dos utentes/cidadãos como das organizações. Neste âmbito, o objecto do Serviço Social confronta-se com um processo complexo de relações sociais no qual se cruza uma teia de relações de natureza política, científica e profissional que abrange a área de actuação profissional, os direitos sociais dos utentes e sua participação.

\section{Dimensão do problema}

Em 2007, segundo Relatório do Instituto de Segurança Social ${ }^{1}$, mais de 11 mil crianças e jovens estavam, em Portugal, em instituições de acolhimento, a maioria das quais há mais de um ano. $\mathrm{O}$ documento faz a caracterização das crianças e jovens, nesse ano, do seguinte modo: 11.362 crianças estavam na situação de acolhimento; $35 \%$ das crianças acolhidas nos Centros de Acolhimento Temporário tinham um tempo de permanência entre um e três anos, quando este não deveria ultrapassar os seis meses. A análise mais detalhada do documento revela que: a maioria das crianças e jovens, em acolhimento, está nessa situação por períodos superiores a um ano; 2.520 crianças, permanecem nas instituições por período superior a seis anos, das quais, 2003 entre quatro e seis anos; 540 crianças, estavam acolhidas há menos de três meses.

A negligência, o abandono, os maus-tratos físicos e a carência socioeconómica são os principais motivos para o acolhimento. A situação de negligência, contudo, é mais significativa, com especial prevalência da ausência de acompanhamento familiar, identificado em 6.137 crianças, e de ausência de acompanhamento ao nível da educação, identificado em 5.388 crianças. Os maus-tratos físicos foram uma realidade para 1.758 crianças e jovens. $\mathrm{O}$ abandono, entendido como a situação em que a criança fica entregue a si própria, surge também como razão para o acolhimento, tendo conduzido, 1.744 crianças às instituições. Cerca de $63 \%$ das crianças e jovens em acolhimento, em 2007, encontravam-se em lares de infância e juventude, um dado que mostra um claro predomínio das respostas de acolhimento prolongado. Em Centros de Acolhimento Temporário, encontravam-se acolhidas 1.843 crianças e jovens, enquanto em famílias de acolhimento havia 1.829. A população acolhida é, maioritariamente, adolescente, sendo que mais da metade dessas crianças tinha mais de 12 anos. Segundo o mesmo Relatório, a maioria das crianças institucionalizadas não tinha qualquer projecto de vida delineado. A Secretária de Estado Adjunta e da Reabilitação, em exercício, referiu que a definição do projecto de vida não é uma mera 
formalidade administrativa, e que o objectivo definido pelo Governo de, até 2009, desinstitucionalizar 25\% destas crianças não pode ser um mero número. Segundo esta, o trabalho consiste na construção de um modelo sustentado que garanta os direitos e as necessidades das crianças.

\section{Modelo de bem-estar social para a infância: perspectivas europeias}

O conceito de bem-estar é, comum ser utilizado na actualidade, como um valor e um direito, relacionado com o desenvolvimento individual e pessoal, com o desenvolvimento social e económico, com vista a uma maior coesão na sociedade globalizada. Quando tratamos o conceito de bem-estar social no domínio da intervenção social, "[...], colocamo-nos na perspectiva do cidadão, portador de direitos que tem esses direitos realizados ou, ao invés, não tem esses direitos realizados devido à sua ausência" (PEREIRINHA, 2008, p. 72).

Assim, podemos definir bem-estar social como sendo o conjunto de medidas, dirigidas à sociedade para satisfazerem as necessidades de pessoas e de grupos. Integra o termo acção social tanto dos poderes públicos, como de todos os agentes que possam contribuir para a melhoria da qualidade de vida dos indivíduos. Em contrapartida a este valor de bemestar, surgem com maior visibilidade na sociedade contemporânea o mal-estar provocado pela crise económica mundial (pobreza, endividamento das famílias, perda do emprego), associado também ao mautrato infantil e à violência doméstica, ambos centrados maioritariamente na família. Segundo Aleman Bracho e García Serrano (2006, p. 230), “Puede hablarse de bienestar en diferentes sentidos: bienestar personal o sociale, politicas de bienestar, Estado del bienestar o servicios de bienestar."

No que respeita ao Serviço Social, tratamos o conceito de bem-estar social como um valor, um elemento constitutivo de uma cidadania plena de toda e qualquer pessoa que, inserida na sociedade, tem como direito humano a possibilidade de acesso às melhores condições e qualidade de vida. O bem-estar social constitui, desde sempre, uma preocupação central no Serviço Social, tendo presente que um dos seus princípios e fundamentos se inscreve na Declaração Universal dos Direitos Humanos, valorizando em particular o direito ao desenvolvimento social e humano. Outro princípio importante, em Serviço Social, designa-se de dignidade humana e autodeterminação, reconhecendo cada ser humano como uma pessoa com capacidades para aprender e reaprender a ganhar novas competências, enquanto membro de uma sociedade humana onde os valores da igualdade e da equidade presidem.

$\mathrm{Na}$ actualidade, o conceito de desenvolvimento ganha importância no campo do desenvolvimento social e local, constituindo-se num novo paradigma de intervenção social. $\mathrm{O}$ sistema de protecção à criança, na sociedade contemporânea, caracteriza-se pela sua universalidade no quadro normativo legal e local e no quadro da efectivação da resposta social aos problemas da criança e da família, exemplo disso são as Comissões de Protecção de Crianças e Jovens $(\mathrm{CPCJ})^{2}$, cuja unidade territorial de intervenção é local (CPCJ, art.15). Neste âmbito, consideramos pertinente definir o conceito de desenvolvimento social e local, o qual integra três dimensões: desenvolvimento pessoal que caracteriza a relação de ajuda com os beneficiários da acção; desenvolvimento social que caracteriza o trabalho centrado nas solidariedades e no tecido social de um território; desenvolvimento organizacional que caracteriza o processo de evolução participativa das organizações e uma nova gestão das políticas públicas.

$\mathrm{O}$ conceito de desenvolvimento situa a acção no quadro da investigação/acção, na programação, no acompanhamento da mudança e na resolução de problemas sociais ou económicos. Desenvolvimento implica, ainda, produção na sociedade, centrado numa lógica de inovação ou de resolução de problemas e uma dinâmica social que coloca no centro da atenção os seus actores e os seus sujeitos. Uma outra dimensão fundamental, a considerar na análise do modelo de bem-estar social, respeita ao desenvolvimento pessoal, centrado na valorização das potencialidades individuais e sua adaptação ao desenvolvimento (área de prioridade local, no que respeita ao primeiro emprego e à perda de emprego).

O desenvolvimento local é um processo colectivo que permite identificar algumas soluções para os problemas económicos e sociais, baseando-se em duas correntes: a corrente económica e social que visa, essencialmente, o desenvolvimento económico e a reorganização do território; e a corrente solidária que procura desenvolver os recursos sociais de forma adequada à resolução das questões sociais comunitárias.

A corrente económica e social, promove a criação de projectos de desenvolvimento local. A corrente de solidariedade, promove a mobilização dos serviços e dos cidadãos (beneficiários) sobre projectos centrados na satisfação das necessidades sentidas pelas comunidades locais e que são apoiadas pelos decisores locais e nacionais.

A partir de 1990, o desenvolvimento humano ganhou maior importância no discurso político e nas práticas profissionais, também, muito reforçada na Estratégia de Lisboa $^{3}$ (2000), com maior associação aos direitos humanos. As Nações Unidas definiram que o desenvolvimento humano,

[...] centra-se no fortalecimento das capacidades e liberdades dos membros de uma comunidade e os direitos humanos, representam as reivindicações 
que as pessoas têm pelo respeito da conduta individual e colectiva ou das estruturas de mecanismos sociais para garantir essas capacidades e liberdades (PNUD, 2001, p. 20).

No quadro da globalização e de uma crise económica mundial, podemos assistir de novo a uma nova crise do Estado de bem-estar social, conforme aconteceu nos finais dos anos 70 do século 20. A crise económica actual tem tendência a um aumento dos problemas sociais, nomeadamente: perda de emprego (no mês de Janeiro de 2009 em Portugal 70 mil pessoas perderam o emprego); endividamento das famílias: aumento da pobreza; e perda de habilitações etc.

Estamos, de novo, perante o debate sobre a capacidade dos sistemas de protecção social se adaptarem às novas realidades económicas e sociais não só ao nível do Estado Membro, mas no quadro da União Europeia. A esse nível, actuam as políticas sociais, principalmente as direccionadas para a protecção social assegurada pelo sistema de Segurança Social, incluindo uma relação de parceria às respostas públicas ao nível da saúde, habitação, educação, emprego e serviços sociais, bem como as organizações não governamentais da sociedade civil. Assim, podemos concluir que a política social é uma forma de promover o desenvolvimento humano e o bem-estar social das pessoas.

Em todos estes problemas, a sociedade e o Estado requerem a actuação do Serviço Social, como forma de promover os direitos humanos e a justiça social enquanto princípios e fundamentos da cidadania. $\mathrm{O}$ objectivo máximo da intervenção do Serviço Social é facilitar e criar oportunidades de desenvolvimento das potencialidades individuais e colectivas para que todo o cidadão exerça as suas competências e responsabilidades sociais e individuais. O Serviço Social, no quadro do paradigma construtivista, desenvolve a sua acção no contexto da construção do conhecimento da realidade. Nesse paradigma, encontramos uma relação forte entre conhecimento e representação, reconhecendo esta como uma mediação que possibilita partilhar o conhecimento produzido, numa perspectiva do desenvolvimento social e humano, na promoção de igualdade de oportunidades e da não discriminação. O modelo de empowerment emerge nos países anglo-saxónicos depois dos anos 1960, no âmbito das organizações comunitárias e, segundo Donzelot (1994), ganha força como conceito de participação nos Estados Unidos.

Este modelo de empowerment não substitui a participação, descreve o processo que o sujeito deve ter em conta no seu projecto individual e colectivo ao nível da comunidade local. Supõe um trabalho centrado sobre a pessoa e sobre as relações interpessoais, isto é, promove na pessoa a capacidade de investimento sobre si próprio e de agir sobre os outros, bem como de aprender a utilizar o colectivo para realização dos objectivos pessoais. Este modelo é retomado nos Estados Unidos nos anos 1980 como reacção aos programas de prevenção centrados só no sujeito sem ter em conta os contextos sociais e as experiências do sujeito, ou seja, procura fazer com os que não têm voz, que adquiram essa voz. Para Aleman Bracho e García Serrano (2006, p. 244), "Los profissionales del Trabajo Social puden contribuir a que las personas sean capaces de dirigir su própria vida o, de lo contrario, pueden convertirse en agentes de violência institucional."

O Serviço Social assume particular papel na integração social, promovendo a participação plena de todo e qualquer cidadão, na vida social, cultural, económica e política, enquanto consequência da efectiva aplicação dos direitos humanos e do princípio de igualdade de oportunidades para todos. O Serviço Social centra-se nas capacidades do sujeito para potenciar competências pessoais, sociais e relacionais que o vão ajudar a exercer a sua cidadania, utilizando os recursos e as políticas sociais activas, promovendo respostas inovadoras, através das redes de solidariedade social e do novo compromisso assente na participação e no reconhecimento da pessoa como parceiro na própria intervenção.

No domínio do modelo de bem-estar social da Europa do Sul, Ferrera apresenta uma definição das características básicas do modelo, como sendo: um modelo corporativista e fragmentado, enquanto sistema interno de manutenção da renda e uma polarização interna de pensões para estratos privilegiados da população. Trata-se de um modelo muito influenciado pela Igreja Católica, onde existe um clientelismo assente nas entidades patronais e na distribuição selectiva de dinheiro e subsídios. A falta de um tipo de administração eficiente e racional, onde predomina uma cultura política e um enfraquecimento da sociedade civil que resulta na burocratização e na regulamentação legislativa.

Nesse quadro de reflexão, é importante verificar que os países do Sul da Europa se caracterizam, maioritariamente, por democracias liberais. Historicamente, são países com um capitalismo pouco desenvolvido e controlado por regimes autoritários, alguns até meados do século 20, dependentes do sector agrícola e, só recentemente, consolidaram um sistema democrático, baseado em princípios de maior igualdade e numa economia redistributiva.

Nos países do Sul da Europa, assinala-se como muito importante o papel da família, na medida em que muitas das obrigações de bem-estar dependem da acção da própria família. A família é, na maioria dos casos, o primeiro prestador de cuidados, destacando-se o papel da mulher. O modelo de bem-estar social da Europa do Sul (Grécia, Portugal, Itália e Espanha) integra, no seu debate, se este se constitui 
como regime por si próprio ou se é um legado das nações que usufruem do modelo continental.

Torna-se, também, importante introduzir no debate analítico nesse modelo, a relação e/ou oposição entre os conceitos de Sociedade Providência e Estado Providência. A Sociedade Providência assenta num princípio de regulação social que se auto-organiza e que presta os primeiros cuidados aos sectores e grupos mais desfavorecidos e vulneráveis da sociedade. Exemplo disso são as Instituições Particulares de Solidariedade Social, as Organizações não Governamentais e as Associações Culturais e Recreativas.

$\mathrm{Na}$ actualidade, a "[...] redefinição do papel do Estado reinscreve na discussão sobre a adequação das funções sociais e económicas desse modelo político à realidade actual da Sociedade [...]" (MOZZICAFREDO, 2002,p. 1). Ainda, segundo o autor, "A matriz institucional do Estado-Providência, na sua dimensão social, não se desenvolve de maneira linear e específica, mas segundo uma série de casos, rupturas das relações sociais e conflitos de interesses."

As políticas sociais dirigidas à criança e à família caracterizam-se de protecção, no que respeita ao acolhimento e internamento em instituições sociais, assumem, na actualidade, um enfoque de políticas keinesianas e liberais.

Para Mozzicafredo (2002, p. 14), o contexto do Estado Providência situa-se em quatro domínios: a democracia,

[...], é uma das dimensões constitutivas do Estado Providência, porque é um processo que a estrutura política incorpora, na matriz constitucional, o enquadramento institucional e político que organiza as funções - respostas e instrumentos de acção que os diferentes sistemas de sociedade colocam ao Estado.

Neste âmbito, Andrade (2001, p. 80), refere que o Estado Providência entra em derrapagem nos anos 1960, quando se torna difícil assegurar progresso social e progresso económico em simultâneo. Citando a autora,

Na sequência da crise económica e política dos anos 70, acontece o declínio das filosofias de suporte, esta concepção do social começa a alterar-se. A forma de agir sobre o social mantendo a complementaridade entre o social e o económico, perde pertinência [...].

De acordo com Pereirinha (1997 apud Andrade 2001, p. 82), o Estado Providência ganhou relevo ao nível do sector informal, ou seja, no domínio da família, reconhecida como suporte social no que respeita aos serviços domésticos e cuidados familiares, onde a mulher assume papel preponderante na sua execução.
A crise do Estado Providência para além de um conjunto de factores exógenos, comporta basicamente duas dimensões endógenas ao sistema - a crise do emprego e a alteração das estruturas familiares [...] é nestes dois eixos base em que, tendo assentado a construção do Estado Providência, neles encontramos sintomas de fractura que abalam todo o edifício social.

\section{Modelos de protecção social à criança e ao jovem em Portugal}

O relatório de actividades da Comissão Nacional de Crianças e Jovens em Risco (Cncjr), de 2006", identificava o sistema de protecção em Portugal em quatro níveis: elevada dimensão de crianças e jovens acolhidos em instituição, permanência longa na instituição de acolhimento, baixa mobilidade entre os diferentes tipos de acolhimento e fluxos de acolhimento de entrada nos sistemas inferiores aos de saída para o meio natural de vida. O Plano de Intervenção Imediata $^{5}$ (PII, 2008, p. 14), confirma a caracterização anterior embora deixe indícios de melhoria nos fluxos de saída do acolhimento institucional para o meio natural de vida:

\begin{abstract}
O peso das crianças e jovens que cessaram o acolhimento, ainda que seja inferior ao número de crianças acolhidas (40\% das acolhidas), tem vindo progressivamente a aumentar [...], representando $28 \%$ do total das crianças e jovens caracterizadas no âmbito do plano de intervenção imediata.
\end{abstract}

Os direitos humanos constituem um dos princípios centrais da intervenção do Serviço Social no sistema de protecção à criança, assim como a convenção dos direitos da criança, assumindo particular pertinência nas práticas dos assistentes sociais, ao nível dos cuidados e tratamento na promoção do bemestar da criança. No domínio da protecção e promoção do bem-estar da criança, de acordo com o Manual da International Federation of Social Workers ${ }^{6}$ (Mifsw, 2002) o Serviço Social deve analisar a aplicação dos princípios expressos da convenção dos direitos da criança, nomeadamente: a não discriminação (art. 2.); o superior interesse da criança (art. 3.); o direito da criança à sobrevivência e ao desenvolvimento (art. 6.); respeito pelas opiniões da criança (art. 12. $)^{7}$. Segundo o Manual da Ifsw sobre o Direitos Humanos e Serviço Social (2002, online),

O Serviço Social tem a sua origem nos ideais humanitários e democráticos. Assim, a prática do Serviço Social está, desde o início, centrada na satisfação das necessidades humanas e no desenvolvimento do potencial e recursos humanos. 
O sistema de protecção social português foi, nas últimas duas décadas, influenciado por tensões internas, num quadro de transformações sociais e na mudança de estatuto social e das condições de vida da criança, configurando uma alteração ao modelo social contemporâneo de protecção social. Segundo Relatório das Comissões de Protecção de Crianças e Jovens (CPCJ, 2008, online), “[...] a infância é necessariamente afectada e influenciada pelas mudanças sociais em curso." A infância desenvolveuse inicialmente como "sentimento" e consolidou-se como "norma universal" relativa ao grupo etário mais jovem com o decurso da modernidade (ARIÈS, 1981; BECCHI; JÚLIA, 1998; HEYWOOD, 2004).

Torres (2008), refere que as alterações do modo de vida da criança, exprimem-se nas mudanças da composição e do estatuto familiar, na reorganização do espaço/tempo de vida quotidiana, nas opções das políticas sociais (nomeadamente no que respeita à crise do Estado Providência e às suas incidências na redistribuição e nas transferências sociais para as famílias), nos progressos tecnológicos e na invasão do espaço doméstico pelas tecnologias da informação e da comunicação e, de forma mais geral, nas mudanças das instituições para as crianças.

\begin{abstract}
Os indicadores sociais das crianças portuguesas exprimem uma realidade paradoxal: a situação global da infância portuguesa melhorou nas últimas décadas, mas são desiguais os desenvolvimentos dessas melhorias, por efeito das desigualdades sociais e porque as medidas de política adoptadas nem sempre são convergentes com os resultados esperados, sendo estes, em alguns casos, manifestamente insatisfatórios (TORRES, 2008, p. 158).
\end{abstract}

Actualmente, verificamos em Portugal a existência de indicadores de bem-estar social no domínio da infância, nomeadamente: a evolução da taxa de natalidade; taxa de mortalidade infantil mínima; combate à pobreza infantil; combate à exploração do trabalho infantil e melhoria nos dispositivos de efectivação dos direitos da criança. (FERREIRA, 1999, 2005; TORRES, 2008). Como refere Torres (2008, p. 160):

Em suma, o paradoxo da infância contemporânea revela-se no facto das crianças concentrarem a esperança colectiva, quando há cada vez menos crianças e o horror toma conta da descrição mediática da sua vida.

Contudo, só nos anos 1980 se começou a dar especial atenção às crianças vítimas de maus tratos e em situação de abandono. Nessa época, surge o debate entre o chamado "modelo de justiça" (que privilegia a defesa da sociedade e o respeito dos direitos, liberdades e garantias dos menores) e o "modelo de protecção" (que privilegia a intervenção do Estado na defesa do menor sem que formalmente lhe esteja reconhecido o direito ao contraditório).

Em 1990, a Convenção sobre os Direitos das Crianças foi ratificada por Portugal, através da Resolução da Assembleia da República n. 20/90, de 12 de Setembro ${ }^{8}$. Foi então que se estabeleceu como prioridades a promoção da família os direitos e a protecção das crianças e dos jovens em risco, sendo criadas, em 1991, as Comissões de Protecção de Menores, as quais foram revistas pela reforma do direito de menores de 1999, conforme Lei n. 147/999.

No sistema Português, existem dois modelos de intervenção subjacentes à protecção social da criança e do jovem. Um modelo de intervenção social directamente relacionado com as Comissões de Protecção de Crianças e Jovens e os serviços locais de acção social e outro de intervenção judicial, relacionado com o Ministério Público, os tribunais, os Centros Educativos da Direcção Geral de Reinserção Social e a Polícia.

O modelo de protecção baseia-se no princípio de que todas as crianças e os jovens com necessidade de protecção têm direito a um plano de integração definitiva, contrariando as práticas habituais de "esperar e observar". O plano de integração definitiva, compreende: a preservação da família; a separação temporária/provisória da criança e do jovem da sua família; separação definitiva da família biológica e colocação em família idónea ou em instituição; a preparação da criança/jovem para a sua independência. A intervenção para a promoção dos direitos e protecção da criança e do jovem obedece a um conjunto de princípios, expressos na Lei n. 147/99, nomeadamente o artigo 4: interesse superior da criança e do jovem; privacidade; intervenção precoce; intervenção mínima; proporcionalidade e actualidade; responsabilidade parental; prevalência da família; obrigatoriedade da informação; audição obrigatória, participação e subsidiariedade.

As Comissões de Protecção de Crianças e Jovens são, actualmente, as instituições por excelência que aplicam o modelo de protecção, através de medidas de promoção e protecção. Estas medidas são executadas em meio natural de vida ou em regime de colocação, consoante a natureza da situação da criança e do jovem. Consideram-se medidas a executar, em meio natural de vida: o apoio junto dos pais; o apoio junto de outro familiar; a confiança a pessoa idónea; apoio para a autonomia de vida; medidas de colocação em acolhimento familiar e acolhimento em instituição.

Torna-se, então, necessário questionar a organização das práticas sociais e a dimensão técnicooperativa das políticas públicas, nomeadamente na redução dos recursos e meios à intervenção social no sistema de protecção social. 
Um dos pilares do sistema de protecção social português são as politicas públicas, especialmente as medidas de política social. Os Serviços Sociais, constituem um serviço público para prevenir e intervir nos problemas sociais emergentes na comunidade local e para facilitar a integração social, mediante recursos sociais (centros, equipas técnicas etc.) de gestão pública e privada. Nessa questão, parece essencial compreender a existência da rede pública de protecção à criança, da rede de solidariedade social, emergente da iniciativa da sociedade civil, e da relação de cooperação e complementaridade estabelecida entre ambas.

O Modelo Educativo, fundamenta-se no princípio da prevenção da criminalidade juvenil e no combate à delinquência dos jovens e desenvolve-se através da utilização de novas modalidades de penas que visam: a prevenção de comportamentos criminógenos; a intervenção precoce desenvolvida por agentes fora do sistema penal; o recurso a métodos que permitam consciencializar os pais, face aos efeitos da violência; o melhor esclarecimento das causas da criminalidade juvenil e do seu funcionamento em gangs. Esse modelo visa permitir à criança e ao jovem o confronto consigo próprio, a reconciliação com a sua história, a compreensão do seu presente e a perspectiva do seu futuro, com as limitações decorrentes do seu nível de maturidade, mas com a consideração máxima da sua dimensão afectiva e intelectual. A intervenção educativa, desenvolve-se com base na pedagogia da responsabilidade e tendo em conta a particular individualidade da criança/jovem com os seus direitos e deveres. Esta intervenção deve, preferencialmente, utilizar: programas que propiciem alterações de comportamentos de orientação cognitiva comportamental e de abordagem psicodinâmica; programas pedagógicos com currículos flexíveis, adaptados às características das crianças/jovens, quer na formação escolar, quer na formação profissional; programas de actividades socioeducativas que facilitem a aprendizagem, a integração na instituição e na comunidade.

\section{Relação dos modelos de bem-estar social com o exercício profissional}

Os assistentes sociais reconhecem que:

[...] nem sempre é fácil aplicar na prática o que está legislado, devido a muitos factores externos, mas tentam cumprir ao máximo. $\mathrm{O}$ assistente social tem a capacidade de se adaptar a todas as situações e delas tirar proveito em prol do bem-estar da criança. ${ }^{10}$

Também consideram que:

[...] os profissionais estão muito limitados na sua praxis porque os modelos de protecção social exis- tentes não promovem o devido bem-estar à criança, sinalizada numa Comissão de Protecção.

Ao nível teórico, referem os assistentes sociais participantes no estudo:

Os modelos de protecção e bem-estar estão bem concebidos.

A dificuldade é operacionalizá-los quando não existem infraestruturas básicas necessárias à sua implementação.

\section{Modelos de protecção à criança em Portugal facilitadores do agir profissional}

Para os assistentes sociais, os modelos de protecção à criança em Portugal:

[...] são facilitadores, uma vez que o seu agir profissional assenta em leis previamente definidas que lhes permitem ter uma base para uma intervenção sustentada.

Alguns dos profissionais inquiridos, dizem que os modelos de protecção

[...] são facilitadores, por um lado, na medida em que definem um determinado modelo para seguir, o que orienta a intervenção profissional, nomeadamente o que fazer, como fazer e quando fazer.

Um dos inquiridos, considerou os modelos de protecção:

[...] de uma forma geral, facilitadores, no entanto, um pouco insuficientes e burocráticos. Exemplo: em caso de emergência, penso que as autoridades policiais deveriam ter mais legitimidade de intervenção.

Para a maioria dos inquiridos:

Os modelos de protecção, em vigor, permitem a estruturação do agir profissional. O tipo de intervenção por níveis delimita fronteiras e define os limites de cada entidade ou serviço. Só depois de esgotada a intervenção pelos serviços da infância e juventude intervém a Comissão e, só depois desta, se entra na esfera judicial.

Concluímos, também, que os assistentes sociais consideram:

[...] existir bons modelos de protecção, embora não sejam colocados em prática por todas as entidades intervenientes. 
Os modelos de protecção, em vigor, deveriam facilitar a acção profissional se fossem bem interpretados pelas instituições e ou profissionais que as representam: a intervenção deve seguir um eixo hierárquico, consoante a necessidade/problema - resposta.

\section{Modelos de protecção à criança em Portugal dificultadores do agir profissional}

Por outro lado, os assistentes sociais consideram também os modelos de protecção:

[...] dificultadores, na medida em que determinam prazos mínimos para a intervenção.

Alguns referem que:

[...] são muito dificultadores, e stressantes, devido à burocracia e pressão de todas as instituições para com a CPCJ.

Consideram, também, que em algumas situações os modelos de protecção:

[...] não são promotores de bem-estar para a criança. Por exemplo: numa situação de abuso sexual quem sai de casa é a criança e não o abusador, logo a criança é duplamente vítima.

Os modelos de protecção vigentes são, também, caracterizados pelos assistentes sociais:

[...] com muitos constrangimentos, por exemplo: numa família as crianças têm processo na Comissão e uma das crianças tem processo noutro serviço. Não promovem uma articulação positiva, nem na perspectiva dos técnicos, nem na perspectiva da família.

\section{Posicionamento crítico dos assistentes sociais face aos modelos de protecção e bem-estar social para a criança em Portugal}

Para os assistentes sociais, os modelos de protecção e bem-estar social para a criança em Portugal,

[...] são adequados. Contudo a sua aplicação prática, vê-se muitas vezes condicionada por falta de recursos a vários níveis (técnicos, físicos, tecnológicos etc.).

Na prática profissional, os assistentes sociais confrontam-se:

[...] com a situação em que nenhuma das respostas existentes, ao nível dos modelos de protecção e bem-estar social, é a ideal para determinada criança ou jovem, existem dificuldades difíceis de ultrapassar ou que se irão manter sempre.

Na opinião da maioria dos participantes do estudo:

As entidades com competência, em matéria de infância e juventude, deveriam ter maior participação no que diz respeito aos modelos de protecção porque, muitas vezes, são a primeira entidade a quem as famílias recorrem ou se apercebem do problema, principalmente as entidades policiais, cujo processo, muito burocratizado, leva as pessoas a pensar que não vale a pena, exemplo: violência doméstica.

Neste momento, considero que as crianças oriundas de famílias problemáticas não têm o apoio que deveriam ter do Estado. Há situações sinalizadas na nossa Comissão que deveriam ter tido uma intervenção precoce, para não chegarem ao ponto que chegaram. O Estado deveria facilitar o acesso destes menores aos serviços de primeira linha e descomplicar a burocracia!

Os modelos de protecção falam-nos no superior interesse da criança. Este conceito indeterminado não se aplica na maior parte das situações. Judicialmente, continuam a ser dadas mais oportunidades aos pais, como proprietários dos seus filhos, do que às crianças.

As Comissões trabalham, muitas vezes, o risco porque os serviços de primeira linha não têm capacidade de resposta. A pirâmide está invertida. $\mathrm{Na}$ base há falta de recursos humanos, materiais, logísticos.

\section{O papel do estado na promoção do sistema de protecção à criança}

A acção do Estado é orientada pelos princípios da igualdade de oportunidades, cidadania, responsabilidade, participação, integração, multiculturalidade e intervenção local, conforme preconizado pelo Instituto Segurança Social em 2007. O Estado reconhece a criança e o jovem como actor social e desenvolve um conjunto de meios de protecção que visam promover os seus direitos individuais, económicos, sociais e culturais. Citando Garcia-Pelayo (1991, p. 93) "[...], o Estado Social é um Estado gestor, sendo em simultâneo distribuidor de valores sociais".

Nesta perspectiva de debate sobre a construção do modelo de estado social, sustentado na crise do Estado Providência, iniciou-se, em 1987, um estudo internacional, no domínio do bem-estar da criança, promovido pelo Centro Europeu de Viena (1987), pionei- 
ro no desenvolvimento da investigação sobre a Infância como fenómeno social, com o objectivo de contribuir para novas políticas de infância a promover, futuramente, por cada Estado membro. A investigação produzida aprofundou o enfoque estrutural no estudo da criança ${ }^{11}$. Ao nível teórico, estamos na presença de um novo paradigma para o estudo da criança, baseado no princípio da construção social como forma estrutural, isto é: estamos perante a ideia que o desenvolvimento da criança é uma estrutura permanente em qualquer sociedade ou comunidade em que viva.

O enfoque estrutural, procura analisar as actividades da criança como construtivas e integradas com as actividades dos adultos, partindo do pressuposto que a criança pertence à sociedade e faz parte das actividades organizadas da mesma. A criança é identificada como pertencente a um grupo minoritário, logo, quem tem o poder de definir o que diz respeito à criança, são os adultos, mesmo contrariando o artigo 12 e 13 da Convenção dos Direitos da Criança.

A família constitui um elemento estruturante do desenvolvimento da criança incontestável, independentemente de ser positivo ou negativo. Actualmente, a precoce institucionalização da criança (aproximadamente 17 mil em Portugal) coloca-a em contacto com outros adultos que se ocupam deles e lhes prestam os cuidados necessários, tornando-se a criança num ser independente do seu grupo familiar, pondo em debate as relações sociais de família. Por outro lado, temos uma sociedade que, ideologicamente e culturalmente, continua a defender a família como meio integrador da criança. No entanto, a realidade diz-nos que as crianças são completamente dependentes economicamente dos pais/da família. As famílias com filhos estão obrigadas a partilhar o seu rendimento salarial com os mesmos. "Como fins do Estado Social, a justiça distributiva, a distribuição de bens jurídicos de conteúdo material e a acção do estado gestor" (GARCIA-PELAYO, 1998 apud CAEIRO, 2008, p. 208). Citação que nos apoia na interpretação de um Estado protector e, em simultâneo, regulador da sua acção numa relação com a sociedade civil, muito presente nas formas de contratualização com as Instituições Particulares de Solidariedade Social (IPSS). Situação, também, presente nas Comissões de Protecção, cuja constituição assume o princípio de representatividade e de colaboração entre serviços públicos, privados, de solidariedade social e pelo próprio cidadão, conforme a Lei n. 147/99, artigos 12, 13 e 17.
O sistema de protecção à criança em Portugal assente no sector da Segurança Social, (Lei de Bases da Segurança Social n. 17/2000, de 8 de Agosto $^{12}$ ), distingue a protecção social de cidadania, a protecção da família e o subsistema previdencial. A Lei de Bases da Segurança Social de 2002 (Lei n. 32/2002, de 20 de Dezembro ${ }^{13}$ ), apresenta um novo modelo em que o Estado deverá assumir um papel progressivamente menor numa óptica de partilha, com as pessoas, da responsabilidade pela cobertura dos riscos sociais, o que se traduz numa maior responsabilização individual dos cidadãos.

\section{Considerações finais}

No domínio da protecção e promoção do bemestar da criança, o Serviço Social analisa particularmente, a aplicação dos princípios expressos da convenção dos direitos da criança, nomeadamente a não discriminação (art. 2.); o superior interesse da criança (art. 3.); o direito da criança à sobrevivência e ao desenvolvimento $\left(\operatorname{art}^{\circ} 6^{\circ}\right.$ ); e respeito pelas opiniões da criança (art. 12.) (MIFSW, 2002). Segundo o Manual da IFSW sobre Direitos Humanos e Serviço Social, "[...], a prática do Serviço Social está, desde o início, centrada na satisfação das necessidades humanas e no desenvolvimento do potencial e recursos humanos (2002, online)."

A efectivação de um modelo de bem-estar para a criança depende das competências técnico-científicas dos assistentes sociais, em particular baseadas no domínio do conhecimento dos modelos de desenvolvimento social e humano no quadro europeu, com vista à promoção de um agir profissional que reconhece as capacidades e competências das pessoas, enquanto sujeitos activos em sociedade.

Concluímos que a adop-

\section{Criança em Portugal estrutura-}

se no sistema de Segurança

Social e no subsistema de

Solidariedade Social,

valorizando a preservação da

família e a manutenção da criança no seio familiar. ção pelo modelo de coordenação aberta, promovido pela União Europeia e pelo Estado português representa um desafio para as políticas públicas de protecção à criança e à família, bem como para a qualificação das práticas profissionais, enquanto instrumento reconhecido como eficaz para a definição de políticas públicas no domínio da protecção social. O modelo de protecção à Criança em Portugal estrutura-se no sistema de Segurança Social e no subsistema de Solidariedade Social, valorizando a preservação da família e a manutenção da criança no seio familiar. O modelo educativo é fun- 
damentado na abordagem preventiva e educativa de comportamentos e condutas antissociais.

\section{Referências}

ALEMAN BRACHO, C.; GARCÍA SERRANO, M. Fundamentos de bienestar social. Valencia, Espanha: Tirant Lo Blanch, 2006.

ANDRADE, M. de C. S. Serviço Social e mutações do agir na modernidade. Tese ( Doutoramento em Serviço Social) - Pontifícia Universidade Católica de São Paulo, 2001.

ARIÈS, P. História Social da criança e da família. Tradução de Dora Flaksman. Rio de Janeiro: LTC,1981.

BECCHI, E.; JULIA, D. Histoire de l'enfance, histoire sans paroles? In: Histoire de l'enfance en Occident - de l'antiquité au XVII siècle. Paris: Ed. Seuil, 1998. (v.1).

CAEIRO, J. M. C. Políticas públicas, políticas sociais e Estado providência. Lisboa: Universidade Lusíada, 2008.

DONZELOT, J. L'intervention du social: essai sur le dèclin des passions politique. Paris: Ed. Seuil, 1994.

FALCÃO, M. do C. Serviço Social: uma nova visão teórica. São Paulo: Cortez \& Morais, 1979.

FERREIRA, J. M. L. Intervenção social e judicial no problema - criança maltratada. Revista Intervenção Social, Lisboa: Cedest, n. 17/18, p. 150-158, 1999.

Questionar as práticas sociais junto da criança/ jovem - da reflexão a uma proposta de intervenção do Serviço Social. Revista Intervenção Social, Lisboa: Cedest n. 30, p. 57-95, 2005.

J. M. L. Serviço Social e modelos de bem-estar para a infância: 'modus operandi' do assistente social na promoção da protecção à criança e à família. 353 p. Tese (Doutoramento em Serviço Social) - Instituto Universitário de Lisboa, ISCTE, 2009.

FERRERA, M. A reconstrução do Estado Social na Europa meridional. Análise Social, Lisboa: Ed. ISCTE, n. 151/152, p. $457-475,2000$.

GARCÍA-PELAYO, M. Derecho constitucional comparado. Madrid: Alianza Editorial, 1991.

HEYWOOD, C. Uma história da infância: da Idade Média à Época Contemporânea no Ocidente. Tradução de Roberto Cataldo Costa. Porto Alegre: Artmed, 2004.
MOZZICAFREDO, J. Estado Providência e cidadania em Portugal. Oeiras: Ed. Celta, 2002.

PAULO NETTO, J. Transformações societárias e Serviço Social. Notas para uma análise prospectiva da profissão no Brasil. Serviço Social \& Sociedade, São Paulo: Cortez, n. 50, ano XVII, p. 87-132, abr. 1996.

PEREIRINHA, J. A. Politica social. Fundamentos da actuação das politicas públicas. Lisboa: Ed. Universidade Aberta, 2008.

PNUD - Programa das Nações Unidas para o Desenvolvimento. Informe Sobre el Dessarollo Humano, 2001. México: Ed. FCE, 2005.

TORRES, A. (Coord.). Estudo de diagnóstico e avaliação das Comissões de Protecção de Crianças e Jovens. Centro de Investigação e Estudos de Sociologia. Instituto Superior de Ciências do Trabalho e da Empresa. Lisboa, fev. 2008.

UNICEF - Convenção sobre os direitos da criança. Adoptada pela Assembleia Geral nas Nações Unidas em 20 de Novembro de 1989 e ratificada por Portugal em 21 de Setembro de 1990. Disponível em: <http://www.unicef.pt/ docs/pdf_publicacoes/convencao_direitos_crianca2004. pdf >. Acesso em: nov. 2008.

\section{Notas}

1 O Relatório do Instituto de Segurança Social, 2007, está disponível em: $\langle$ http://www.seg-social.pt $>$.

2 As CPCJ são constituídas e funcionam nos termos da Lei n. ${ }^{\circ}$ 147/99. São instituições oficiais nãojudiciárias com autonomia funcional que visam promover os direitos da criança e do jovem e prevenir ou pôr termo a situações susceptíveis de afectar a sua segurança, saúde, formação, educação ou desenvolvimento integral. Disponível em: <http:// www.cncjr.pt >.

3 Disponível em: <http://www.planotecnologico.pt/ default.aspx?site=estrategiadelisboa $>$.

4 Disponível no Relatório da Cncjr de 2006 em: <http:// www.cncjr.pt $>$.

5 O Plano de Intervenção Imediata (PII) é um documento elaborado anualmente pela Segurança Social e entregue à Assembleia da República dando conta da situação das crianças e jovens em acolhimento. Disponível em: <http:// www.cnpcjr.pt/preview_documentos.asp?r=1117\&m=PDF>.

6 Disponível em: <http://www.ifsw.org/cm_data/Portu gese_version.pdf $>$. 
7 Conforme aLei de Protecção de Crianças e Jovens em Perigo, Lei n. 147/99, de 1 de Setembro. Disponível em: <http:// www.malhatlantica.pt/ecae-cm/Lei147-99.htm>.

8 Disponível em: <http://diario.vlex.pt/vid/setembro33169163>.

9 VerNota 7.

10 Todos os depoimentos, e partes de depoimentos, aqui transcritos foram obtidos para a pesquisa original do autor (FERREIRA, 2009).

11 Centro Europeu de Viena, cujo projecto inclui dezasseis relatórios referentes aos países: Canadá, Checoslováquia, Dinamarca, Inglaterra e Gales, Finlândia, Alemanha, Grécia, Irlanda, Israel, Itália, Noruega, Escócia, Suécia, Suíça, Estados Unidos e Jugoslávia (1987).

12 Disponível em: <http://www.apdt.org/guia/L/LSs/ Lbasss.htm>.

13 Disponível em: <http://www.mtss.gov.pt/preview_ documentos.asp? $\mathrm{r}=292 \& \mathrm{~m}=\mathrm{PDF}>$.

\section{Jorge Manuel L. Ferreira}

socialjorge@sapo.pt

Doutorado em Serviço Social pelo programa doutoral do Instituto Universitário de Lisboa (ISCTE)

Professor auxiliar no Instituto Superior de Serviço Social de Lisboa (ISSSL) da Universidade Lusíada de Lisboa

Professor auxiliar convidado no ISCTE

Universidade Lusíada de Lisboa - ISSSL

Rua da Junqueira, 188-198

1349-001

Lisboa - Portugal

\section{ISCTE - Instituto Universitário de Lisboa}

Av. Forças Armadas

1649-026

Lisboa - Portugal 